\title{
AOR
}

Selected Papers of \#AolR2020:

The $21^{\text {st }}$ Annual Conference of the

Association of Internet Researchers

Virtual Event / 27-31 October 2020

\section{"TWO CAN PLAY AT THAT GAME": COMMUNICATING DISSENT AS A MICRO-CELEBRITY IN A RESTRICTED NATIONAL TWITTERSPHERE}

\author{
Ozlem Demirkol Tønnesen \\ University of Southampton
}

\section{Background}

Turkey has a notoriously restricted online sphere where sharing any anti-government content can have serious repercussions such as imprisonment (Saka, 2018). Yet for those who oppose the government, Twitter still remains the primary space for antigovernment political discourse and mobilisation. Especially during political events such as elections, visibility of these narratives on Twitter becomes a top priority in order to mitigate the erasure of anti-government viewpoints from the mass media. However, the criminalisation of online dissent creates a tension between this desire for visibility and the need for self-preservation. In this context, a lot of responsibility falls on those accounts who are the most visible on Twitter, while also being more exposed to the surveillance mechanisms. This research explores the expressive political participation by high-visibility Twitter users (micro-celebrities) in an effort to reveal the tactics they use in mitigating these tensions.

Amidst a surge of academic studies on micro-celebrity and Influencers on social media in recent years (see. Abidin and Brown, 2018), Twitter micro-celebrity remains an under-researched phenomenon. Studies that look at micro-celebrity on Twitter often focus on public figures and traditional celebrities (Giles ,2016; Bennet and Thomas, 2014; Marwick and boyd, 2011) or micro-celebrities that offer a form of expertise such as medical doctors (Chandawarkar et al., 2018). This trend persists in the research on micro-celebrities' political expressions where the focus is mainly on the activist accounts and the "usual political suspects" (Wright et al., 2012) such as journalists and politicians. However, these actors reveal very little about the pressures of censorship that the ordinary citizens experience as their reflections on politics are often presented from a professional or issue-specific standpoint.

In order to capture the everydayness of political talk, I focus on a genre of microcelebrity that gained popularity among anti-government users primarily through their witty, relatable and humorous depictions of everyday life under the AKP government. 
These once ordinary users gained popularity specifically during 2013 Gezi Park protests when they were sharing witticisms, narrating the events and disseminating key information about the protests. To this day, their on-point observations and clever narration of everyday events under AKP provides comic relief to those who hold similar views. Over time, these accounts claimed a significant command of the vernacular Twitter culture and their tweets became a regular source of inspiration for many memetic expressions that others use when talking about similar topics including politics. Thus, as accounts that openly oppose the government, the ways they mitigate the dangers of visibility on Twitter can have significant implications for the language that is used in this discourse.

\section{Methods}

As these accounts engage in anti-government political talk on an as and when basis, I wanted to capture a time period when political events and news are frequent. An opportunity has arisen as the government announced early elections in April 2018 and set the election date only 3 months in the future, which generated a lot of debate. Thus, I have set the data collection period as the 3-months leading up to the 2018 Presidential Elections. I have created a private Twitter list of 97 micro-celebrity accounts that I have gathered through purposive sampling. During the campaign period, I have closely followed this list, gathered common memes, took screenshots and compiled a list of prominent events that were widely discussed. I have also scraped the tweets daily through Web data research assistant tool. Employing an interpretive content analysis was necessary as in a majority of these tweets critical content was presented inexplicitly. I have first decided which tweets were elections-related and assigned codes according to their purpose (criticism, support, call to action etc.). Then used a second set of codes to document the evasion tactics and implied accusations in critical tweets.

\section{Findings and Discussion}

Findings show that on Turkish Twitter, micro-celebrities' political talk relies on platformspecific cultural capital in formulating a language that is understood by subgroups who are acclimated to the platform culture. I argue that the primary aim here is to produce content that cannot be decoded by pro-government accounts who are responsible from much of the surveillance on Turkish Twitter. In this sense, the weaponisation of the platform culture supports the previous arguments on the perceived gap in cultural capital between pro- and anti-government groups (Irak, 2018). This gap can be linked to the government framing of Twitter as a source of evil and not being on Twitter as good citizenship.

On Twitter, the platform culture is built on creative strategies such as play and humour to overcome expressive restrictions imposed by the platform (Papacharissi, 2012). My findings show that these characteristics of the platform become tools to achieve temporary reversals of power (Scott, 1990) when the oppressors lack the necessary knowledge to decode such content which became second nature to regular users. For instance, appropriation of the vernacular Twitter language and the Western popular culture which includes drawing subtle comparisons between movie villains and the 
President, references to early Internet phenomena, captioning viral videos with implied political messages etc. has become the cornerstone of this powerplay between those who hold the cultural knowledge and those who hold the political power.

I argue that, in this restricted environment, the forced confinement of dissent in the online platforms and the need for visibility have given those who can command both the attention and the platform culture the power to shape the political discourse. Adoption of this playful language and "tactical frivolity" (Kingsmith, 2016) on social media and beyond (see. recent campaigns of opposition parties) shows that platform-specific literacies are becoming essential for those who want to be heard and also be safe when expressing political grievances. This inevitably creates a generational and socioeconomic divide by giving the agency to those who are "in on" these online conventions. Therefore, the ways micro-celebrities mitigate expressive restrictions need further attention as, especially in repressive settings, the platform-specific literacies they share with their audience have power to define who gets left out of these discourses.

\section{References}

Abidin, C. and Brown, M.L. eds., 2018. Microcelebrity around the globe: Approaches to cultures of Internet fame. Emerald Group Publishing.

Bennett, J. and Thomas, S., 2014. Tweet Celebrity: Forum: Tweet Celebrity. Celebrity Studies, 5(4), pp.501-503.

Chandawarkar, A.A., Gould, D.J. and Stevens, W.G., 2018. The top 100 social media influencers in plastic surgery on Twitter: who should you be following?. Aesthetic surgery journal, 38(8), pp.913-917.

Giles, D.C., 2017. How do fan and celebrity identities become established on Twitter? A study of 'social media natives' and their followers. Celebrity studies, 8(3), pp.445-460.

Irak, D., Digital cultural capital as a counter-hegemonic tool in Turkey.

Kingsmith, A.T., 2016. Why so serious? Framing comedies of recognition and repertoires of tactical frivolity within social movements. A journal for and about social movements, 8(2), pp.286-310.

Papacharissi, Z., 2012. Without you, I'm nothing: Performances of the self on Twitter. International journal of communication, 6, p.18.

Saka, E., 2018. Social Media in Turkey as a Space for Political Battles: AKTrolls and other Politically motivated trolling. Middle East Critique, 27(2), pp.161-177.

Scott, J.C., 1990. Domination and the arts of resistance: Hidden transcripts. Yale university press. 